\title{
BIOÉTICA, BIOPODER E ACESSO À SAÚDE
}

\section{BIOETHICS, BIOPOWER AND HEALTH ACCESS}

\section{Paulo Jorge Nazaré Correia ${ }^{1}$}

\begin{abstract}
Resumo: A Bioética é um privilegiado espaço teórico de humanização da tecnologia. O progresso científico tem vindo a colocar nas mãos da humanidade um poder cada vez maior de produzir, modificar, selecionar e direcionar. Os novos recursos tecnológicos geram mudanças rápidas. Aumentam as questões sobre o presente e o futuro, em termos de vida consistente e digna para os seres humanos, para as diferentes formas de vida e para o seu meio ambiente. Acompanhando este processo de transformação, a reflexão ética procura delinear as bases da sobrevivência com dignidade. A Bioética é a ciência que tem como objetivo indicar os limites e as finalidades da intervenção do Homem sobre a vida, identificar os valores de referência racionalmente proponíveis, denunciar os riscos das possíveis aplicações. Discute a vida e a saúde humanas, como tal, não interessa apenas a todos os homens, bem como requer, para essa discussão, a bagagem do conhecimento de todos os que estão ligados à área da saúde. Para se trilhar um caminho correto diante dos diversos dilemas éticos, precisa-se de uma "base sólida", de um fundamento, que oriente nos momentos de decisão. O presente trabalho consiste numa revisão da literatura, com pesquisa em bases de dados eletrónicas, e tem como objetivo refletir acerca da Bioética, do biopoder e da promoção da saúde. Com base na revisão da literatura, concluiu-se que a Bioética ligada à Saúde Pública procura a proteção dos usuários no que concerne aos direitos humanos, principalmente o mais essencial: o direito à saúde.
\end{abstract}

Palavras-chave: Bioética; biopoder; promoção da saúde.

\begin{abstract}
Bioethics is a privileged theoretical space for the humanization of technology. Scientific progress has been putting in the hands of mankind an ever greater power to produce, modify, select and direct. The new technological resources generate rapid changes. They raise questions about the present and the future in terms of consistent and dignified life for humans, for different life forms and for their environment. Accompanying this process of transformation, ethical reflection seeks to delineate the basis of survival with dignity. Bioethics
\end{abstract}

\footnotetext{
${ }^{1}$ Mestre em Gestão - Universidade Católica Portuguesa. E-mail: pnc747@ gmail.com
} 
is the science that aims to indicate the limits and the purpose of human intervention on life, to identify rationally pro - posable reference values, and to denounce the risks of possible applications. It discusses human life and health, as such, does not concern only all men, and requires, for this discussion, the baggage of the knowledge of all who are connected to health. In order to find a correct path in the face of the various ethical dilemmas, a "solid base", of a foundation, is needed that guides the moments of decision. The present work consists of a review of the literature and aims to reflect on Bioethics, biopower and health promotion. Based on the literature review, it was concluded that Bioethics linked to Public Health seeks to protect users with regard to human rights, especially the most essential: the right to health.

Keywords: Bioethics; biopower; health promotion.

\section{INTRODUÇÃO}

Estamos hoje na era da Bioética e esta tornou-se uma referência indispensável em todas as áreas da saúde. Alguns abusos na experimentação em seres humanos, o surgimento de novas tecnologias que colocam questões inéditas e a perceção da insuficiência dos referenciais éticos tradicionais, desencadearam o seu aparecimento.

A Bioética é essencialmente um novo modo de pensar, a partir da dignidade humana como valor fundamental, tendo sempre em atenção as regras que salvaguardem o Homem na mais plena realização de si próprio. Deste modo, em saúde tem de se assegurar a dignidade da pessoa, sendo reconhecida como um ser único, onde os seus direitos e autonomia devem ser preservados (Potter, 2001).

$\mathrm{O}$ rápido desenvolvimento da Bioética levou a que nem sempre o desenrolar das suas reflexões se baseasse nos mesmos modelos teóricos, sendo estas muitas vezes decididas de acordo com as influências (filosóficas, religiosas, etc.) que cada bioeticista possuía. Não é, por isso, de estranhar que tenham surgido vários modelos de teorização. Desde modelos utilitaristas, comunitaristas, Kantistas ou deontológicos, até ao modelo principialista, foram muitos os modelos defendidos de acordo com os vastos legados culturais e filosóficos de cada área.

O debate bioético, a procura de fundamentação para a emissão de juízos éticos, o acolhimento de argumentos oriundos de distintas ciências, a morosa, mas segura elaboração de uma linguagem própria, assumem-se como fenómenos de incontestável verdade. Por conseguinte, a Bioética não se confina a um encontro académico de especialistas de várias áreas do 
saber e da atividade profissional, preferencialmente oriundos da Biologia, da Filosofia, da Teologia, do Direito e da Medicina, constituindo-se como uma "transdisciplina", com projeção numa perspetiva mais lata de saberes e de práticas próprios. Desta feita, a Bioética, como recente configuração da preocupação com o estudo sistemático das dimensões morais da conduta humana nas ciências da vida e nos cuidados de saúde, tem de se constituir como uma presente e constante dinâmica de formação ao nível dos profissionais relacionados com a área da saúde.

Partindo-se do pressuposto que a Bioética se transformou significativamente no plano das mentalidades da cultura de hodierna, como resposta aos alucinantes avanços tecnológicos e às profundas transformações sociopolíticas de um mundo em processo de globalização e de multiculturalismo, assume-se que é extremamente importante abordarse a Bioética, o biopoder e a promoção da saúde. Para tal, seguiu-se uma metodologia de revisão da literatura, procurando-se refletir acerca da Bioética, do biopoder e da promoção da saúde.

\section{EMERGÊNCIA DA BIOÉTICA}

O vocábulo Bioética é comummente referenciado como a ética aplicada à vida, significado que, inclusive, se afere da sua etimologia: Bio (vida) e Ethos (ética) (Koerich, Machado \& Costa, 2005). Porém, esta é uma definição pouco precisa, resultando na necessidade de se fazer uma resenha histórica, ainda que sumária, sobre a sua origem, a qual é muito recente.

Karl Van Rensselaer Potter, oncologista da Universidade de Wisconsin em Madison foi quem usou, pela primeira vez, em 1970, num artigo intitulado "Bioethics, the science of survival", o termo Bioética, posteriormente desenvolvido no seu primeiro livro "Bioethic: bridge to the future". Segundo o mesmo autor, o objetivo último desta disciplina era "não só enriquecer as vidas individuais, mas prolongar a sobrevivência das espécies humanas em uma forma aceitável de sociedade" (Potter, 2001, p. 19). Havia em Potter uma preocupação pela vida alargada à ecologia, isto é, a preocupação pela necessidade de um estado ambiental ótimo e uma adaptação humana que permita uma sobrevivência harmoniosa.

Paralelamente, e sem que tivesse conhecimento do uso do vocábulo, André Hellegers apresenta similarmente a sua utilização associada à criação do "Joseph na Rose Kenedy Center for Study of Human na Bioethics", embora com um sentido ligeiramente diferente do de Potter (2001). 
Para Hellegers, a bioética é a ética aplicada às ciências da vida consideradas ao nível do humano, sendo particularmente uma ética biomédica que devia o seu impulso "aquilo em que se tinha tornado a medicina num mundo em que a saúde e a doença se tinham transformado em conceitos profundamente confusos" (Potter, 2001, p. 343).

Embora esta seja uma visão um pouco reducionista da bioética, todavia, esta foi prevalecendo ao longo do vasto período da existência desta disciplina.

Em 1988, Potter apresenta uma reformulação da sua definição de bioética, ou seja, substitui-a pela ideia de "Bioética global" e, posteriormente, atualiza-a como "Bioética profunda". Assim, dentre os vários assuntos já dominantes da bioética, até então, introduz algumas preocupações com a indispensabilidade de saúde para todos no mundo, sem quaisquer discriminações, a diminuição da mortalidade infantil e taxas de controlo da reprodução humana voluntariamente controladas, a convivência harmoniosa com a natureza, entre outras preocupações (Potter, 2001). Surge, deste modo, como um desafio quer para as profissões em geral, científicas e médicas em particular, quer para as religiões. O desafio racional de formular e providenciar valores, ou seja, suscitar o questionamento no sentido de se saber que valores se defendem e como podem ser apropriados. De acordo com o autor suprarreferido, este é o desafio ao despertar de uma nova consciência de se ser, de um apurado sentido do humano, que se interroga pelo "que devo fazer?" face ao "que posso fazer?"

Por conseguinte, a bioética terá de ser vista neste sentido global Potteriano, englobando, por isso, aspetos como a ecoética, biopolítica, bioética médica, ética empresarial, biodireito, etc., já que a preocupação principal é a vida humana e esta não pode ser vista fora do mundo em que está inserida.

Serrão (1998, p. 12) apresenta a seguinte definição, escutada por Archer, que diz "Bioethics is love of life" e que, apesar da sua simplicidade, nos parece possuir profundidade, dado que só amando a vida, a poderemos estudar ininterruptamente com respeito e responsabilidade, que nos possibilite modificar uma nova visão de felicidade, paz e harmonia em realidade.

Hellegers (s.d., cit. por Reich, 1995, p. 19-34) admitiu que a bioética seria "a única disciplina combinando ciência e ética. $\mathrm{O}$ componente da ciência incluiria as ciências biológicas e as sociais; e o da ética incluiria uma ampla gama de éticas religiosas e seculares", isto é, via a transdisciplinaridade e transversalidade em ciências e áreas em que a vida 
e a saúde são tratadas como a pedra angular desta disciplina.

Serrão (1998, p. 12) define o método desta disciplina como "Complementaridade", aludindo às leis da física e, particularmente, a Niels Borh, físico Dinamarquês que formulou o denominado "princípio da complementaridade", o qual refere que no interior de um átomo, a matéria apresenta-se com aparente dualidade, ora comportando-se como partículas, ora como ondas. Embora pareçam duas realidades contraditórias, elas não se anulam uma à outra e, por essa razão, se complementam.

À semelhança, na Bioética, este método consiste na "complementaridade" de dois pontos de vista divergentes sobre o ser humano e sobre tudo o que o envolve, como é o caso do olhar metodológico das ciências biotecnológicas (natureza biológica do homem) e das ciências humanas, sociais e filosóficas (homem de natureza reflexiva).

Neste contexto, o objetivo da Bioética será a síntese epistemológica de todo este pensamento, acentuando, em similitude, duas estruturas e cooperar no melhoramento das condições de vida todos os seres humanos.

Nesta linha de pensamento, a Bioética constitui-se por uma enorme transdisciplinaridade e transversalidade, no que concerne às ciências e áreas em que a vida e a saúde são o ponto fulcral (Pessini, 2013).

Apesar de a Bioética ter unicamente três décadas de existência, esta evoluiu de forma bastante célere. Assim, desde o surgimento do termo e da procura de significação, à generalização do seu uso, ao aumento de obras publicadas, estudos e opiniões, até à difusão dos comités nacionais de ética para as ciências da vida, tudo se processou de forma galopante.

A Bioética assume-se como uma disciplina basilar na defesa dos verdadeiros valores do progresso da vida humana. A organização deste novo saber desenvolveu-se com tal rapidez e ponderância, que estes escassos anos bastaram para que se transformasse numa referência imprescindível para a medicina, biologia, filosofia, teologia moral, sociologia, direito e até para a ação política internacional (Archer, 2006).

De acordo com Archer (2006), encontram-se três fatores históricos fundamentais que terão contribuído para esta emergência Bioética, os quais se apresentam seguidamente. Alguns abusos na experimentação com seres humanos. Este problema assoma imediatamente à Segunda guerra mundial, com o conhecimento público das atrocidades "científicas" praticadas pelos médicos nazis que sujeitaram coercivamente a experiências uma desmesurada quantidade de judeus, que se encontravam nos campos de concentração. De acordo com o referido autor, são incontáveis os relatos destas experiências. A título exemplificativo 
salientamos alguns: indivíduos submetidos a temperaturas extremas para se avaliarem os limites humanos; experiências com tóxicos, para se saber os tempos e doses de atuação; Joseph Menguele, médico nazi, aplicava corantes químicos nos olhos dos prisioneiros para mudar de cor.

Certo é que a descoberta destes factos levou a que passados poucos anos, mais concretamente em 1948, a Organização das Nações Unidas tivesse proclamado a Declaração Universal dos Direitos do Homem, onde, entre outros aspetos, delibera que nenhuma experiência seja executada sem consentimento livre e esclarecido.

Todavia, apesar desta declaração, estes abusos não se resolveram, e dessa data até à atualidade assistimos a relatos de excessivos abusos de experimentação com seres humanos, que resultam numa grande atividade por parte dos comités nacionais e internacionais de ética (Koerich, Machado e Costa, 2005):

- Nos EUA e na antiga União Soviética, expuseram-se propositadamente grupos de pessoas a radiações atómicas para perceber os seus efeitos.

- Nos EUA um grupo de negros não teve qualquer tratamento para a sífilis, para que se pudesse estudar as várias fases de desenvolvimento da doença.

- Muitos laboratórios farmacêuticos elegem populações carentes e pouco esclarecidas para a realização de testes científicos, sem qualquer benefício.

- O primeiro bebé criado por injeção intracitoplasmática é o resultado de experimentação humana.

Presentemente, com o desenvolvimento das biotecnologias e, em particular, da engenharia genética, irrompem novas ameaças de abusos, sobretudo pela incerteza dos resultados, tais como a clonagem humana e terapêutica, bem como a terapia genética (Koerich, Machado \& Costa, 2005).

De acordo com os autores supracitados, Hans Jonas introduziu o conceito de ética da responsabilidade. Para ele todos têm responsabilidade pela qualidade de vida das futuras gerações. Foi ele também que abordou o conceito de risco e a necessidade de avaliá-lo com responsabilidade. Potter, representante da Bioética, também se mostrava preocupado com os riscos que podem ser causados pela ciência em nível mundial. Para o autor, o conhecimento pode ser perigoso, entendendo o conhecimento perigoso, como aquele que se "acumulou muito mais rapidamente do que a sabedoria necessária para gerenciá-lo" e sugere que "a melhor forma de lidar com o 
conhecimento perigoso é a sabedoria, ou seja, a produção de mais conhecimento e mais especificamente de conhecimento sobre o conhecimento (Koerich, Machado \& Costa, 2005, p. 108).

Tendo-se em conta a abrangência atual da Bioética, destacam-se quatro aspetos considerados relevantes e que estimulam uma reflexão teórica mais ampla entre as ciências da vida, ou seja, uma Bioética da vida quotidiana, que se refere aos comportamentos e às ideias de cada pessoa e ao uso das descobertas biomédicas; uma bioética deontológica, com os códigos morais dos deveres profissionais; uma Bioética legal, com normas reguladoras, promulgadas e interpretadas pelo Estado, com valor de lei e uma Bioética filosófica, que procura compreender os princípios e os valores que estão na base das reflexões e das ações humanas nestes campos (Beauchamp \& Childress, 1994).

Para a abordagem de conflitos morais e dilemas éticos na saúde, a Bioética se sustenta em quatro princípios. Estes princípios devem nortear as discussões, decisões, procedimentos e ações na esfera dos cuidados da saúde. São eles: Beneficência, Não-Maleficência, Autonomia e Justiça ou Equidade.

Paralelamente à reação aos abusos científicos e igualmente sociopolíticos, de importância no mundo da pesquisa clínica e no contexto social, a sociedade, como um todo, começou a deparar-se, devido ao aumento progressivo da complexidade dos procedimentos médicos e dos custos associados, com dilemas até há pouco inexistentes (Santos, 2014).

\section{A PROMOÇÃO DA SAÚDE SOB O OLHAR DA BIOÉTICA VS. BIOPODER}

A promoção da saúde, como campo de formulações teóricas, mas, principalmente, como espaço de manifestações práticas na tessitura social, requer uma aproximação analítica das possíveis implicações éticas consequentes da sua aplicação. Assim sendo, considera-se que quer a Bioética Quotidiana, quer a Bioética da Proteção se assumem como referenciais de análise consistentes para produzir tal reflexão. A primeira, porquanto procura refletir sobre as situações da vida quotidiana que abrange milhões de pessoas e que são permanentemente ocultas, omitidas ou negligenciadas. A segunda, pois ocupa-se de questões referentes ao fortalecimento das ações que têm como finalidade a proteção da qualidade de vida e da saúde humana. Em ambos referenciais da bioética, dois elementos se apresentam e se aproximam, quais sejam, os princípios da 
responsabilidade e da autonomia. Como todo processo em construção, os riscos apresentam-se e as críticas são fundamentais para as formulações conceituais de promoção da saúde. Nesta ótica, um dos riscos mais evidentes diz respeito à possibilidade de políticas públicas de saúde serem construídas de modo reducionista, transfigurando os problemas sanitários complexos em desvios de conduta individuais, deslocando quer o cerne da questão do corpo social para o corpo biológico ou físico, quer a responsabilidade da produção de respostas efetivas do nível do Estado para o próprio indivíduo. Este reducionismo ajuda a explicar porque que razão vários programas de promoção de saúde orientam as suas estratégias para a promoção de uma conduta sadia.

A sustentabilidade do sistema de saúde tem sido um tema muito debatido na atualidade, constituindo-se como um dos objetivos basilares das políticas de saúde a garantia da sustentabilidade do sistema. Esta questão volta a colocar-se porque há um crescimento forte da despesa associado a um não crescimento ou crescimento débil da economia.

Importa ressalvar que a sustentabilidade técnica consiste na capacidade técnica de prestar os cuidados de saúde necessários à população, e a sustentabilidade financeira, grosso modo, refere-se à capacidade de pagar os cuidados que querermos ter. Todavia, a sustentabilidade financeira, encarada como a capacidade de pagar cuidados de saúde, jamais pode ser desligada das outras opções de utilização do rendimento disponível, quer se esteja a falar do sistema de saúde, quer do serviço nacional de saúde.

No nosso país, face à conjetura de pressão económica, taxa de desemprego elevada, aumento das prestações sociais, concorrência pelo espaço orçamental, atividade económica reduzida e menor espaço orçamental, têm sujeito à Saúde um conjunto de racionamentos, cortes e ajustes no seu financiamento, o que implica um apurado estudo acerca do impacto do investimento em Saúde. A insustentabilidade financeira do Sistema de Saúde surge no topo dos problemas identificados, quando analisada a área da Saúde em Portugal. As causas são várias, desde a inovação e modernização tecnológica à pressão demográfica.

O investimento em Saúde é efetuado através de financiamento público e privado, o que assume grande relevância para análise do nível absoluto destes e do rácio entre si, resultando num investimento que objetiva a melhoria no nível de Saúde da população expressa através de mortalidade, morbilidade e qualidade de vida. Por sua vez, os resultados positivos no nível de Saúde da população são transmitidos à Economia particularmente por meio de três mecanismos: aumento da população ativa, participação acrescida na economia, e melhorias na produtividade da força laboral. 
As dificuldades orçamentais exercem forte pressão sobre a despesa em cuidados de saúde feita pelo Estado, ocorrendo pressão para medidas de efeito imediato, contudo as medidas administrativas podem resultar em perigos, com base na experiência passada, resultando na descredibilização dos mecanismos de controlo, no acúmulo de dívidas e na possível reentrada nos ciclos de orçamentos retificativos.

Os custos e a insustentabilidade financeira do Serviço Nacional de Saúde têm sido um tema em debate por parte de sucessivos Governos a fim de justificarem os cortes orçamentais que penhoram o desenvolvimento do Serviço Nacional de Saúde. Esta é uma visão da insustentabilidade do sistema de saúde. Porém, não há excelência se não houver sustentabilidade, a qual tem implícita uma boa gestão da saúde, no que se refere ao investimento na prevenção, na criação de saúde e Well being. Porém, este processo requer ajustada adequação dos recursos às necessidades, a diminuição do erro/fazer bem à primeira e a redução do desperdício (estrutural e operacional). Por outras palavras, há a necessidade de haver um controlo de custos/retorno de investimento.

A Saúde, sob um ponto de vista académico, é um dos principais vetores de desenvolvimento económico de uma sociedade, devendo, no entanto, ser contextualizada e analisada numa perspetiva holística desse progresso, tendo-se como ponto de partida a diversidade de outros fatores e as suas inter-relações, nomeadamente: o capital humano, as infraestruturas, a competitividade regional, a sustentabilidade ambiental, a inclusão social, a saúde, a segurança, a formação/qualificação, entre outros fatores, que convergem para o desenvolvimento económico. Mas, este é um processo que exige uma clara definição do indicador agregado de medição de sustentabilidade do Sistema de Saúde, através da a) metodologia de research e análise, que tem inerente a aplicação da didática ajustada à obtenção e análise de conhecimento já produzido, visando a redução da curva de aprendizagem e a potenciação da obtenção dos resultados propostos; b) da disponibilidade de dados, isso é, a utilização competente dos dados quantitativos e qualitativos disponíveis, de modo a poder formular-se e validar-se as propostas traçadas, originando estes fatores na capacidade de modelação da realidade, um caminho viável para a garantia da sustentabilidade do sistema de saúde, que deve assegurar os recursos necessários à melhoria dos padrões de saúde da população, através da concomitante adaptação dos recursos às necessidades dos cidadãos, assente no controlo de custos e no retorno do financiamento. Esta poderá ser uma via capaz de agregar condições para que se possa ter um Sistema Nacional 
de Saúde sustentável e equidade no acesso à saúde.

A sustentabilidade do sistema de saúde apresenta características distintas da sustentabilidade financeira do Serviço Nacional de Saúde, do mesmo modo que esta difere da sustentabilidade financeira de cada entidade do Serviço Nacional de Saúde. Numa perspetiva de sistema de saúde, não importa garantir a sobrevivência de cada instituição ou organização por si, mas garantir que há uma rede de prestadores, em que a maior eficiência de uns leva ao seu desenvolvimento e crescimento e à saída de outros ${ }^{2}$.

O direito à saúde está sempre mais afetado pelas novas configurações do biopoder, cujas intervenções acabaram por não ser determinadas exclusivamente pelo Estado, mas, principalmente, pelo poder simbólico do mercado (Junges, 2009). O mesmo autor salienta que a crescente tecnicização da medicina, com aparelhos, exames e medicamentos de última geração, aliada à ideologia da saúde perfeita e à resultante tendência cultural de identificar saúde com o consumir produtos que vendem saúde, originam um progressivo aumento de gastos induzidos por essa tendência que o orçamento público não consegue suprir. Certo é que o exercício do direito à saúde tem sido particularmente mais determinado pelas estruturas do biopoder, um conceito desenvolvido por Foucault (1979).

Se antes o biopoder se revelava através de uma visão de gestão calculadora, por parte do Estado, da vida biológica dos corpos e das populações, atualmente o biopoder revela-se como gestor simbólico das técnicas ao serviço da saúde por parte das empresas biotecnológicas. Nos dois casos está presente o controlo do biopoder. O primeiro mais direto, numa perspetiva biológica, e o segundo, mais subtil, de carácter consumista e simbólico (Junges, 2009).

Essa nova configuração do biopoder resulta numa perceção do direito à saúde meramente como o acesso e o consumo de tecnologias, relegando-se os determinantes sociais da saúde como um direito dos cidadãos e um dever do Estado, sendo esta uma perspetiva que resulta na compreensão, noutra ótica, o problema da universalização e focalização do sistema nacional de saúde. A focalização nos serviços consistia na forma de realizar a universalização do acesso de cada pessoa ao sistema de saúde, e não se tratava de uma díade de contradição, mas complementar. Todavia, de

\footnotetext{
2 Plano Nacional de Saúde 2012-2016. Roteiro de Intervenção em Sustentabilidade em Saúde (2014). Direção-Geral da Saúde. Acedido em: http://1nj5ms2lli5hdggbe3mm7ms5.wpengine.netdnacdn.com/files/2014/12/2014_15_Sustentabilidade-em-saude.pdf.
} 
acordo com Junges (2009), devido ao biopoder, a universalização e a focalização podem estar a ser adulteradas pela visão tecno-semiológica, respondendo simplesmente a requisitos particulares de consumo de tecnologias.

A força do biopoder tecno-semiológico tem-se manifestado grandemente com a introdução da lógica do mercado - responder a crescentes procuras individuais do consumo em saúde - num sistema público como o sistema nacional de saúde, demonstrando que a simples denominação de estatal não garante que um serviço tenha relevância pública (Heiman, Ibanhes \& Barboza, 2005).

Importa referir que o Estado Providência teve a sua origem no modelo Bismarckiano e no modelo Beveridgeano, apesar de possuírem conceções ideológicas diferentes, acentuaram a importância de um amparo. Deste modo, é importante a existência de uma rede de proteção social de modo a minimizar-se as dificuldades sociais, consequência do crescimento e do desenvolvimento económico. Atualmente, estes modelos continuam a influenciar os sistemas de saúde. Embora se verifique que, em Portugal, a evolução dos sistemas de saúde tenha vindo na direção da redução da intervenção direta do Estado Providência, continua a verificar-se um sistema público, financiado por impostos, que funciona como seguro público, universal e obrigatório. O Estado Providência continua analogamente prestador de serviços de saúde e proprietário de uma parcela significativa do sistema. É imprescindível que Portugal, como membro da União Europeia, um espaço económico e social relativamente comum, tenha como objetivos primordiais das políticas de saúde a equidade, a eficiência técnica e a eficiência económica.

Em suma, as reformas de saúde que se têm operado em Portugal têm estado e continuarão a estar dependentes da situação macroeconómica, do ambiente político, da própria sociedade e das influências externas.

\section{METODOLOGIA}

Com este trabalho, pretende analisar-se criteriosamente a bibliografia científica existente, no âmbito da Bioética, do biopoder e da promoção da saúde.

Existem diferentes abordagens possíveis para o estudo de um determinado fenómeno, dependendo do que se quer descobrir. A revisão da literatura foi a metodologia selecionada, uma vez que fornece diversas perspetivas sobre um determinado fenómeno e tem sido defendida como 
de extrema importância para a ciência e a prática profissional (Medina \& Pailaquilén, 2010).

A prática baseada na evidência é uma abordagem que permite a resolução de um problema, incorporando a procura da melhor e mais recente evidência científica. Deste modo, a revisão da literatura constituise como um dos métodos de pesquisa mais utilizados. Tem como finalidade reunir e sintetizar resultados de pesquisas sobre um determinado tema ou questão, de forma sistemática e ordenada, contribuindo para o aprofundamento do conhecimento do tema investigado (Mendes, Silveira \& Galvão, 2008).

Do enquadramento teórico sobre o fenómeno em estudo e com o estabelecimento da área problemática derivam ideias centrais que colaboram na identificação da finalidade que orienta esta investigação, cujo objetivo consiste em refletir acerca da Bioética, do biopoder e da promoção da saúde.

A pesquisa seguinte foi realizada em pesquisas eletrónicas nas seguintes bases de dados: A estratégia de pesquisa recorreu às seguintes bases de dados eletrónicas: Medline ${ }^{\circledR}$ (via PubMed®), CINAHL ${ }^{\circledR}$ Plus e LILACS ${ }^{\circledR}$ (Literatura Latino-Americana e do Caribe em Ciências da Saúde), Cochrane Database of Systematic Reviews, Cochrane Central Register of Controlled Trials e Nursing \& Allied Health Collection: Comprehensive.

\section{RESULTADOS}

Com base na revisão da literatura efetuada, verificou-se que, nas sociedades plurais e secularizadas observa-se, ao longo das últimas décadas, uma mudança de paradigma na prestação de cuidados de saúde, sendo exemplo disso as constantes adaptações éticas, jurídicas, legislativas e culturais aos avanços constantes das ciências biomédicas. A necessidade de obtenção de conhecimento, informação é o rosto visível dessa transformação.

Os avanços na tecnologia da saúde aumentaram dramaticamente a capacidade de prolongar a vida. Por causa destes avanços surgiram dilemas éticos e legais, à medida que se instituíam terapias complexas para manter as funções vitais, mesmo quando não há qualquer esperança de reverter o processo de doença.

A pessoa doente deixa de ser um sujeito passivo, mero recetor de cuidados, para passar a ser um parceiro ativo no diálogo com uma equipa multidisciplinar, corresponsável no processo de promoção, manutenção e 
recuperação da sua saúde.

A ética envolve diversos fatores concernentes ao valor da ação humana, seja ela uma ação consciente, racional, e mais importante com liberdade de escolher e executar as suas ações e pensamentos. Portanto, sabendo-se que a ética norteia todo o sentido da vida é imprescindível uma reflexão nos mais variados setores da sociedade, nos quais se encaixa a Bioética. Muitos conflitos que envolvem a "dignidade" humana podem surgir, como o aborto, a fecundação artificial, a clonagem, a ordem de não reanimar, entre outros.

Hoje em dia, o aumento da expectativa de vida e sobrevida dos indivíduos, que sofrem algum tipo de doença crónica tem gerado dúvidas; perante o avanço tecnológico e aperfeiçoamento da medicina, a Bioética, "tem sido muito discutida nas questões de humanização e bem-estar total nas relações interpessoais e de cuidado" (Pontes et al., 2010, p. 69). O dilema com tratamentos que aumentam a expetativa de sobrevida criam conflitos, pois trata-se da vida, englobando fatores a serem pensados, quando envolve dimensões da morte, como o morrer, a dor e o sofrimento.

Por norma, as políticas públicas para a saúde não funcionam o que se deve a três elementos principais: não se identificou o fator social concreto determinante da saúde de determinada comunidade; não se conseguiu alvejar e denominar o fator comum que permeia os distintos problemas de saúde em determinado local; não subsiste consenso acerca da direção da transformação social indispensável para alterar as condições sanitárias de determinada população.

Por esse motivo, será erróneo aplicar-se a linguagem moral da medicina clínica para se poder refletir acerca dos desafios éticos da saúde pública. Os princípios da bioética clínica - autonomia, beneficência e justiça - foram pensados para enfrentar problemas de relações entre as pessoas e não podem ser transferidos para o âmbito público da saúde, porquanto se perde a sua especificidade coletiva e social. A ética da saúde pública deve ter um discurso baseado em valores coletivos e sociais.

A Bioética pretende contribuir para que as pessoas estabeleçam "uma ponte" entre o conhecimento científico e o conhecimento humanístico, de modo a evitar-se os impactes negativos que a tecnologia pode ter sobre a vida, uma vez que nem tudo o que é cientificamente possível é eticamente aceitável. Devido à influência histórica, cultural e social que sofremos, devemos estar muito atentos, caso contrário, corremos o risco de perder os parâmetros que devem nortear o acesso à saúde para que as atitudes sejam éticas. Assim, deve entender-se qual o fundamento que se deve ter para 
orientar os processos de decisão, a fim de que as influências negativas não prejudiquem as ações em termos de saúde. Esse fundamento é o reconhecimento da dignidade da pessoa humana, como um ser único e que deve ser considerado na sua totalidade, numa visão holística. Devem utilizar-se os princípios éticos adequados para definir quais devem ser as atitudes, sem esquecer o fundamento. $\mathrm{O}$ primeiro princípio a ser seguido deverá ser o de beneficência/não maleficência, o segundo o de autonomia e o terceiro o de justiça.

Por outro lado, é importante ressalvar que, à luz do biopoder de gestão simbólica das novas biotecnologias em vender mercadorias e procedimentos sofisticados que afiançam saúde, é indispensável que se repense o significado e o alcance do direito à saúde. Continua a persistir uma tendência em reduzi-lo à exegese individual dos direitos defensivos perante o Estado, ou seja, está patente a ideia de que o Estado limita a liberdade do acesso ao consumo de produtos que vendem saúde, ao não fornecê-los.

\section{CONCLUSÃO}

Concluiu-se que o direito à saúde está a ser inserido nos direitos políticos e civis. Mas, inversamente, se o direito à saúde consiste num direito social, então o mesmo é parte integral d e inalienável aos direitos prestativos, impondo uma resposta e uma estruturação coletiva para a sua efetivação. Por conseguinte, o mesmo direito não pode ser protegido sem a interdependência e a indivisibilidade com os outros direitos, principalmente os sociais.

A perspetiva consumista pretende circunscrever o direito à saúde à relação clínica entre médico e cliente, quando é, acima de tudo, um assunto de saúde pública, porque estabelece uma interdependência com os direitos sociais. Por esse motivo, a bioética da saúde pública, tendo como referência a ética a proteção dos direitos sociais prestativos, não os princípios clássicos da bioética clínica, consegue refletir, com mais afinco, acerca do alcance e sobre as implicações do direito à saúde, que é um direito claramente estabelecido em documentos relevantes como a Declaração Universal dos Direitos do Homem, a Constituição Portuguesa ou nos documentos emanados pela Organização Mundial de Saúde.

Importa, antes de se dar por terminado este trabalho, referir que há escassez de literatura que relacione a Bioética e o biopoder ao nível da promoção da saúde, como tal, sugere-se a elaboração de mais estudos, nomeadamente de natureza qualitativa onde se possa dar voz aos vários 
agentes da saúde, procurando conhecer a sua perceção acerca do fenómeno em estudo.

\section{REFERÊNCIAS BIBLIOGRÁFICAS}

Archer, L. (1998). Bioética: avassaladora, porquê? Revista Brotéria, 112: 449-471.

Archer, L. (2006). Da Genética à Bioética. Coimbra: Gráfica de Coimbra.

Archer, L.; Biscaia, J.; Osswald; W.; Renauld, M. (2001). Novos Desafios à Bioética. Porto: Editora Porto.

Beauchamp, T.L; Childress, J.F. (1999). Princípios de Ética Biomédica. Barcelona: Ed. Masson S.A.

Heiman, L.S., Ibanhes, L.C., \& Barboza, R. (Orgs.). (2005). O público e o privado na saúde. São Paulo: Hucitec.

Junges, J.R. (2009). Right to health, biopower and bioethics. Interface Comunic., Saúde, Educ., v.13, 29, 285-295.

Koerich, M.S., Backes, D.S., Scortegagna, H.M., Veronese, A.M., Zeferino, M.T. et al. (2005). Tecnologias de cuidado em saúde e enfermagem e suas perspectivas filosóficas. Revista de Enfermagem; $15,178-85$.

Medina, E.U., \& Pailaquilén, R.M.B. (2010). A revisão sistemática e a sua relação com a prática baseada na evidência em saúde. Rev. Latino-Am. Enfermagem; 18(4): [08 telas].

Mendes, K.D.S, Silveira, R.C.C.P., \& Galvão, C.M. (2008). Revisão integrativa: método de pesquisa para a incorporação de evidências na saúde e na enfermagem. Texto Contexto Enferm, Florianópolis; 17(4), 758-764.

Pessini, L. (2013). As Origens da Bioética: do Credo Bioético de Potter ao Imperativo Bioético de Fritz Jahr. Rev Bioét; 21:, 9-19.

Pontes, A.C., Espíndula, J.Á., Do Valle, E.R.M., \& Santos, M. (2010). Bioética e profissionais de saúde: algumas reflexões. Revista Bioethikos, 1(1), 68-75.

Potter, K.V. (2001). Bioética, abrangência e dinamismo, In ANJOS, Márcio Fabri - Bioética- alguns desafios. São Paulo, Brasil: Edições Loyola.

Potter, K.V.R. (2001). Bioética global e sobrevivência humana, In Bioética - alguns desafios. São Paulo, Brasil: Edições Loyola.

Reich, W.T. (1995). The Word Bioethics: its Birth and the legacies of Those who shape it. Kenedy Institute of Ethics Journal, 5, 19-34. 
Santos, M. (2014). Princípios básicos de bioética aplicados em economia da saúde e em auditoria médica. J Bras Econ Saúde; 6(2), 97-101.

Serrão, D. (1998). Ética em cuidados de saúde. Porto: Porto Editora. 